\title{
The Poetics of Meaningful Work: an Analogy to Speech Acts ${ }^{1}$
}

Meaningful work refers to the idea that human work is inherently meaningful beyond its aim of fulfilling necessary ends. Work, in other words, is an integral part of the way humans think of their lives as going well. The concept has its roots in Aristotle's account of capability and Abraham Maslow's (1994 [1971]) psychological research on human nature and self-actualization. Studies in psychology and sociology that build on this research tend to focus on practical application (e.g. Bailey and Madden 2015; Chalofsky 2003), and this approach has gained more coverage as businesses begin to see how satisfaction about meaning in work correlates with increased individual productivity (e.g. Lau 2000; Steger et al 2012: 323, 333). In philosophy, the discussion tends to revolve around political questions, especially on matters of justice and whether the State should take steps to eradicate or lessen the presence of meaningless work (e.g. Arneson 1987; Roessler 2012; Sayer 2009; Veltman 2016; Walsh 1994; Yeoman 2014).

However, there is on my view a serious lacuna in the general literature that I will discuss in terms of conceptual and historical assumptions. My worry is that while citing evidence of work's meaningfulness, the literature does not really give an account of how the relation between the operations of work and flourishing is achieved. In other words, what remains unexplored is the causal or mechanistic relation (loosely put) between what is being done in and by work and the actualization, exercise, or development of capacities we deem valuable. So as we might think of how work produces objects, one can say there remains an unanswered question in the literature about how meaningfulness is produced by work. I think drawing an analogy to speech acts can be very helpful here, and this would involve seeing meaning production as a kind of poetics.

The poetics of work can be said to involve two levels. On the one hand, meaning arises with respect to instrumental and conventional ends. On the other hand, work tends to drive beyond meansends relations that were not originally anticipated at the first level. As we will see, I argue that the second level is crucial to the human capacity for creative innovation since it allows for new ontological 
possibilities (in the Heideggerian sense) for human existence. I will refer to the two levels respectively as the constitutive and extra-constitutive dimensions of meaning, where the former involves meaning constitution according to rules of instrumentality and conventionality and the latter meaning constitution above and beyond these rules.

By employing an analogy to speech acts, I will give an account of how we can better understand work not simply as producing meaning but predicating it. As we will see, this approach has distinct advantages with regard to the way it situates work within a field of communicability that is limited to neither merely what values one associates with work (conceptual assumption), nor to a reduction of human existence to material relations (historical assumption). I aim to develop this poetics from Paul Ricoeur's hermeneutics where he argues, vis-à-vis J. L. Austin's theory of speech acts, that like discourse, action has locutionary, illocutionary, and perlocutionary features that refigure (change) our relation to the world. The upshot is that by expanding on Ricoeur's theory of action to include work, we will see how work is a unique type of action with distinct locutionary, illocutionary, and perlocutionary capacities for creating meaning.

Because exploring the analogy will require threshing out quite a bit of detail, I offer here a summation of my argument. The constitutive dimension of work involves its instrumentality and conventionality, or more specifically, what we will see are its locutionary and illocutionary meanings. Locution has to do with properly instrumental ends and illocution with conventional ends that meet normative expectations about the quality of performance. ${ }^{2}$ Despite the difference between instrumentality and conventionality, locution and illocution both involve constitutive rules of making and using: the former constitutive rules of instrumentality; the latter constitutive rules of conventionality. The extra-constitutive dimension pertains to effects that extend beyond the instrumental and conventional. I referred to these above in terms of ontological possibilities for existing, and they should be taken to involve novel interpretations of what it means to be and how we understand ourselves, the world, and others. These effects are perlocutionary since, as we will see, they arise as a kind of by-product of work. 
The essay is divided into five sections. The first section provides a brief justification of my claim that the general literature on meaningful work only assumes work to be meaningful. The second section examines the nature of work via the analogy to speech acts, while the third provides more detail about the extra-constitutive dimension of work. The final section concludes by way of highlighting work's extra-constitutive function in view of human capabilities.

\section{The Assumption that Work is Meaningful}

The assumption that work is meaningful comes in at least two varieties-a conceptual assumption relying on associations made with respect to human flourishing and a historical assumption based on Marx's account of work's objectifying function. Both assumptions share in the general characterization that meaningfulness is linked in some way to necessity. The conceptual assumption presents a weak thesis on necessity since it emphasizes how work plays an unavoidable role in the development of our attitudes about well-being (e.g. Attfield 2001: 46; Roessler 2012: 91; cf. Yeoman 204: 241-242). On this view, many other kinds of activity can perform this role; however, because work is something we cannot escape, it requires that we give it serious attention. The historical assumption presents a strong thesis insofar as it takes work's role to be ontologically necessary. That is to say, work is fundamental to the formation of ourselves and the world. Work is indispensable, and no other activity can replace its formative function.

a) the conceptual assumption

The conceptual assumption involves associating work with the development or exercise of things constitutive of human flourishing-e.g. autonomy, self-esteem, virtue, self-respect, etc. Much of the general literature is devoted to demonstrating why these associations are important, with controversy arising in how we are to order, rank, or edit the list of these features (Attfield 2001, Veltman 2016, Walsh 1994). Reflection on and observation of occupations as well as worker testimony are prime sources of evidence. 
Philosophical accounts that involve this assumption tend to overstep an account of meaningfulness because they have other concerns in view. This omission is reasonable within the confines of debates focused solely on justice. For example, Ruth Yeoman (2014: 236) uses the premise that work creates and sustains meaning in order to argue a normative claim that 'meaningful work for all [ought to be] a political project' (2014: 236). In his work on contributive justice, Andrew Sayer (2009: 2; cf. Gomberg 2007: 152) treats work generally under the umbrella of doing. As with other activities, work is a manner of doing in life that 'has as much influence on who we become and the quality of our lives'. Like Yeoman, Sayer (2009: 2; 2011, 10-11) assumes a link between work and the effect it has on well-being and self-development. Anca Gheaus and Lisa Herzon (2016: 70) discuss this benefit widely in terms of the manner by which the 'goods of work can be read as unpacking the ways in which work can be meaningful'. Such discussions are important in conceiving how the availability of meaningful work might be nurtured. My concern is that the conceptual associations made between work and aspects of flourishing remain assumed. Little is said about how work achieves these ends, and so it becomes questionable, on the one hand, as to whether we can in fact make these claims and, on the other hand, as to why we should think work is any different than the other activities that promote flourishing (cf. Nicholas Smith 2007: 193).

But the problem does not simply appear to be one contingent upon how the debates about justice have been shaped. A possible reason why the association occurs, and which would need more development than I can give it here, is that work is at root conceived as a physical endeavour. Linking it to human flourishing often involves attempting to draw relations to activities that involve mental activity (reasoning, imagining, etc.). Hence, James Murphy (1993), Adrian Walsh (1994), and Paul Gomberg (2007) refer explicitly to meaningful work as a relation between theory and practice. Yet the task of relating the physical act to the intellectual, for a lack of better terms, requires more than just an association of the two and more than just describing the two as local to instances of work. We might want to refer to this as the work-flourishing gap which calls for an account of how the former 
produces the latter. As we will see, what the analogy to speech acts provides is a way of rethinking the phenomenon of meaningfulness as an action (cf. Cavell 1995: 50-51).

b) the historical assumption

If Marx has established work as an activity distinct to the human species being, it can be tempting simply to rely on his account as having observed something true about the nature of work (e.g. Muirhead 2004: 13-14). In fact, his account is somewhat straightforward. The production of things in work allows human beings to reflect on themselves. So objectification in work means that as we labor, we come to recognize ourselves and our capabilities (Marx 1988: 107-08). It is only work that can do this since it is only work that involves the use of material as the medium of selfconsciousness. In fact, all other relations depend upon what we fashion in work because all other relations build upon material necessity. Marx therefore does indeed give an account of how work produces meaning, and he also shows how work is not only unlike any other activity but is foundational.

Given how social relations of production have developed beyond the conditions on which Marx was reflecting, allegations are made that his account is not relevant in an age where work does not necessarily produce an object. Service work in particular often comprises a significant portion of a developed nation's economy. ${ }^{3}$ But there are also other forms of labor, such as acquisition, exchange, and speculation that do not produce objects. Responding to these criticisms, Sean Sayers (2007) argues that the identification of Marx with a 'productionist' account of labor is inaccurate and fails to take notice of certain philosophical subtleties that Marx retains from Hegel. In particular, the formative nature of labor does not narrowly mean labor that forms objects but rather that any act of labor is formative of the human spirit (Hegel) or consciousness (Marx). In short, any act of labor is an act that transforms the human relation to nature and thus the human self-understanding. Sayers' defense need not be applicable only to Marx, but to any philosophy using a so-called classical productionist account. ${ }^{4}$ 
Given the breadth of Marx's view, a philosophical analysis of meaning requires merely assuming his argument. Honneth notes, for instance, that this assumption is 'a classic motif' that

always took it as a given that socially established forms of labor were not only to be judged according to whether their execution is recognized appropriately, but also according to whether their structure and organization provide chances for self-realization. (Honneth 2007: 359)

Though critical of this motif, Honneth (2007: 359-360) admits that it is adequate at a basic level when attempting to address broad concerns about justice and work. It is in fact easy enough to frame Marx's diagnosis of the exploitation of labor and the problem of meaningless work in terms of the recognition theory at the heart of Honneth's critical thought. Insofar as work is exploitative and fails to act as a means to flourishing suggests that laborers are reified as commodities instead of recognized as the genuine factor of value creation (cf. Honneth 2008: 75-85; 2007: 343-344). And while it may tend towards strong views about a perfectionism focused on creating non-alienating work across society, it nonetheless functions as a sound critical foundation for arguing how current modes of work may be alienating and require revision (Nicholas Smith 2009).

Apart from this critical, diagnostic virtue, there is a problem with how Marx takes work to be ontologically foundational and therefore indispensable. There is a short and long version of this problem. The short version is simply that Marx's identification of work with necessity neglects a further investigation of what other operations might be innate to work and contribute to the role of meaning production that are not reducible to necessity.

The longer version makes more of this neglect. Marx cannot really account for work's extranecessary role because it would result in a contradiction. ${ }^{5}$ If self-realization arises only through addressing material necessity, any content Marx attempts to give to this process struggles to free itself from being determined by this necessity. Why? Because material necessity acts as a constraint on 
what can be considered authentic. Ideal content risks abstracting the relation to material necessity, and can even risk contradicting it, as in cases where ideology assumes a primary evaluative position. In fact, Marx (1976: 958-59) can only bluntly associate work with something ideal like freedom but cannot delineate how what is most fundamental to us in terms of meeting material necessity can ever be linked to a freedom that is distinct from it. Either freedom really only is a mode of work, or work is in some sense merely a means to a categorically distinct mode of freedom. Marx may provide us with the conceptual tools to recognize the conditions of alienating labor, but his philosophy of work can only gesture towards how non-alienating work does more than merely meet material needs. ${ }^{6}$

So what is at stake in these two assumptions? On the one hand, the conceptual assumption clearly confronts problems with respect to its evidence that work is meaningful. First, by relying on testimony observation, it opens itself to criticisms of subjectivism (cf. 'subject-dependence' in Walsh 1994: 23637; Veltman 2016: 111), where the meaning of work derives from one's attitudes or preferences. And in this sense, derivation is not meaning at all but merely the expression of attitudes or preferences. ${ }^{7}$ However, the problem of subjectivism is only symptomatic of a more fundamental one. Second, in whatever way one wishes to employ evidence, citation of it does not explain the relation between flourishing and work (cf. Cavell 1958: 182) but merely presupposes it. The general literature provides a great deal of analysis of how aspects of human flourishing can be linked to work. Yet nothing apart from work's necessity makes it a unique candidate for producing such flourishing. ${ }^{8}$ Does this mean that even with citation to evidence, the conceptual assumption reduces to a relation of expression (between work and concepts of flourishing)? I think it does not only if we can provide an account of how that relation develops.

As we have seen, the historical assumption attempts to provide this account with respect to a strong thesis about work's relation to material necessity. However, as I have attempted to show, while this identification between work and necessity gives it prominence by virtue of its being indispensable to human existence, it has a severe shortcoming. To define work as a necessary activity, 
without further clarification of how it participates in extra-necessary ends or meanings, reduces work to a servile dimension. Work is thus fated to play the role of the 'other' in relation to activities we might associate with freedom and meaning. Marx recognizes this problem and attempts to remedy it, though on my view insufficiently. Work may indeed be fundamental but only as a means to an end distinct from its material aim. So is there a way of conceiving work as not only capable of but integral to the actualization of meaning in existence-i.e. meaning that is neither simply an expression of one's attitudes nor a reduction to the fulfilment of necessary ends?

\section{The Analogy to Speech Acts}

Why analogy? Taking aspects of language as analogous to work provides a heuristic advantage. The analogy will allow us to avoid the tendency of thinking work is narrowly tied to necessity. So the analogy is speculative, allowing aspects of speech acts to illuminate the way work operates when generating meaning. I will draw on Ricoeur's (1973b: 91) own use of the analogy when conceiving meaningful action as a text (fixed discourse). While he relies on distinctions made by J. L. Austin (1975) and Anthony Kenny (1963), my analysis of speech acts is limited to Ricoeur's application of aspects of these different theories. Consequently, I do not engage with the wider debates about speech act theory; though, I do draw on literature that Ricoeur does not treat in order to clarify my own contributions or to help distinguish my understanding of his position from others. Furthermore, I do not treat Ricoeur's arguments for seeing action as discourse-like but recapitulate his key points in order to show their relevance for rethinking the nature of work. Bearing this in mind, Ricoeur uses speech act theory to argue that action has locutionary, illocutionary, and perlocutionary dimensions. My primary aim in this section is to show how Ricoeur's analysis of action allows us to see something unique about the way human work operates. Indeed, we can speak of work as predicating meaning with respect to locution, illocution, and perlocution. Respectively, these meanings are instrumental, conventional, and extra-constitutive. 
a) locution

The locutionary dimension of action concerns its propositional content. Here, the act of doing is analogous to an act of proposing something about a state of affairs (Searle 1969: 26). ${ }^{9}$ If locutions are constative in that they utter something about a state of affairs (such as, 'It is raining'), Ricoeur (1973b: 99; cf. Kenny 1963: 156-57) maintains that action also proposes in this way due to the polyadicity of the verbs of action. No action is merely indifferent or vacuous, and this is because as a 'reader' of an action, we drive towards a better understanding of the relations and specificities involved in an action and which therefore constitute a description of what is occurring. What may seem a vacuous action - such as 'Plato taught' - is really elliptical since the action draws our attention to clarifying questions: for example, 'whom did Plato teach?' or 'what did Plato teach?' (Kenny 1963: 157). The process of following the action as a reader is possible because we take action to be saying something about a state of affairs that either elicits our curiosity or requires clarification. Extending this analogy, Ricoeur (1973b: 100) maintains that the sense-reference relation that opens discourse to analysis (Austin 1975: 109) can be found in action. That Plato taught someone relies on the senses of the actor and action that are read with respect to a specific situation: Plato taught Glaucon about justice. It is worthwhile noting that Ricoeur (1986: 256) views action as already expressive, to use John Searle's (1969: 26) term, by virtue of it being symbolic, or value-laden, to put it crudely. The analogy here requires, of course, that there is no vicious circularity in representing action linguistically in order to argue that action is meaningful according to certain linguistic features. So to observe the action that Plato taught is meaningful requires speaking about the action as 'Plato taught'. While Ricoeur is silent on this requirement, it is nonetheless consistent with his invocation of the hermeneutic circle to say that the explanation of something like an action involves an understanding whose medium is language (Ricoeur 1973b: 116-117). An action is only action because it can be signified, that is, represented as something outside the immanent flux of existing. ${ }^{10}$

I think there is much more than Ricoeur considers that can be borrowed from speech acts to show how action is propositional. We can see this when considering how work proposes. If 
propositions are stated when speakers utter sentences, then the unit of the proposition is the sentence (Searle 1969: 29). Likewise, the unit of work can be said to be the task. Consider that a task proposes that an end be achieved, and furthermore that that task achievement involves a worker using objects to achieve an end. In this sense, the propositional nature of work involves a kind of 'saying' that is a doing-namely, a doing to achieve an end by way of the use of a tool. Units of work, or tasks, then can be seen distinctly in relation to specific ends that a job or role require. I will stress here that the locutions of work involve the use of equipment, or what is in the most general sense the employment of a tool or tools in view of an instrumental end. ${ }^{11}$

The subject-verb-predicate structure of sentences then has an analogous structure in work: worker-tool use-instrumental end. On this view, instrumental ends are not merely notional for a worker but are envisioned according to a specific means that is ready-to-hand (Heidegger 1962: 98/69). In fact, we often find that we cannot think of such ends apart from specific tools. Digging a hole can scarcely be thought about absent the idea of using a spade or shovel. We might think of using our hands, but this tends to be consequent on not having access to a suitable tool. And although we may envisage an end we want to achieve abstractly and then find the appropriate equipment to achieve it, the equipment is the means by which we have an articulated relation to what we want and how we want to achieve something. In work, intention does not remain general but is specifically tied to equipment. For example, Julia may have the general intention to cut the grass, but the given tool will allow her to come into a specific relation to this end, or what I am saying allows Julia to articulate this end in a special way. Does she use shears? a push mower? an electric mower? Does she want to mulch as well as mow? Perhaps she prefers the agility of a zero turn mower? So although we can speak generally of intending to mow the lawn, in the means-end relation distinct to work, the equipment used in work articulates a specific relation to how the means allows us to achieve the end. It is this process of articulation that I want to call the propositional content of instrumental meaning appropriate to the locution of work. When end and equipment come together, what is 'said' in the act of work is how someone is going about achieving an end. 
Furthermore, if the locution of work is defined by proposing something by means of achieving an end with equipment, then we can see that work involves two kinds of rules that will later help us to distinguish illocutionary and perlocutionary meanings. If work involves both the production of a work object (or how a person plans to make it) and the use of this object (or how a person plans to use it), then another way of describing this relation is to say that it involves complementary constitutive rules of making and using. On the one hand, there are methods and procedures to follow in making a thing of work, such as a mower. On the other hand, these methods and procedures have their end not just in satisfying the standards of a custom of craft or skill, ${ }^{12}$ but also the satisfaction of rules of use according to which a thing of work is applied or consumed by its user. As a species of action we can say that work is unique because the propositional content of work resides in how an act of making as well as an act of using are linked to instrumental ends, or what we can summarize as instrumentally constitutive rules of making and using. In fact, the expectations of what go into making and using at this level suggest that the locutions of any one kind of work can be encapsulated by what are often listed on under the label 'job descriptions. ${ }^{13}$ As we will see, the remit of the coupling makingusing becomes much broader with respect to illocution and perlocution, where ends are no longer instrumental.

b) illocution

The illocutionary dimension of action-what is done in the act of doing-refers to what takes place when performing an action and how it refers to conventional rules and meanings, or what is often termed as the sphere of practice or function (Searle 1969: 125). So what occurs in the performance of an action is with reference to rules of action; performative acts draw on and refer to rules constituting how an action should be done. Referring to the well-known example of promising, Ricoeur comments that 'to understand what a promise is, we have to understand what the 'essential condition' is according to which a given action 'counts as' a promise' (Ricoeur 1973b: 100; cf. Searle 1969: 149). By referring to constitutive rules of what counts as a promise, the act of promising is 
neither indifferent nor vacuous, to use Kenny's phrase, but drives towards an intended meaning or end. Actions like promising, or more widely culturally specific actions, therefore have an illocutionary force only because they can refer to and follow rules that allow them to '[bring] about the state of affairs represented by its propositional content' (Searle and Vanderveken 2005: 111). This force may involve something like proposing to commit a certain deed at a specified time: 'I promise to return the borrowed sum of money on Tuesday.' Without rules to refer to and follow, the act of promising would be nonsensical.

With respect to work, we can say that distinct from instrumentality (locution), the illocutionary force of work is revealed in terms of a wider range of meanings and ends that are conventional-that is, pertaining to the constitution of a shared world of values and norms. This wider range emphasizes the normative inflection of how an act of work achieves its end. So what counts as a conventional use or application is related to the quality of performance when meeting an instrumental end. Is the performance in line with what we expect of someone in that role? Scooping ice cream, for example, is an instrumental end; but illocution-wise we might have certain standards about how the scoop sits atop the cone. How does scooping ice cream count as having created an ice cream cone?

Another example: if we take the manufacturing of a chair, at one level there are conventions that attached to whatever instrumental end a particular chair might be used for. A chair used for relaxing will call up conventions relating to what one expects when relaxing. Should I be able to recline? Should the chair be specifically conducive to reading? At another level, the chair will inevitably be involved in conventions relating to location, practice, and other norms. A chair for relaxing does not stand by itself but fits within a location relationally defined by tables and lamps, which may form the space next to the fireside. Generally, Arendt (1958: 137) refers to the conventional role of work as its 'durability', or the way in which work maintains a space of human relations and meanings. ${ }^{14}$ More specifically, we can note that the two levels of convention correlate with the rules of making and using. That is to say, we can find conventions 'parasitically' attaching to the instrumental rules of 
making, or what we expect beyond instrumental ends, and to rules of using, or what we expect of actions of work with respect to social and existential values. To recall, I referred to these at the outset as constitutive rules of convention with respect to making and using.

In concluding this sub-section, it is worth noting that the rules of making and the rules of using do not have equal epistemological status. The rules of making are much more constricted in the sense that they apply to knowledge of how a thing is made and ought to be made in the procedural sense. Along the lines of speech act theory, we might even say that the rules of use are entailed by the rules of making, where the rules of making specify conditions according to which the rules of use can be executed..$^{15}$ Yet, if the rules of use may derive from rules of making, we see that they are not confined to them. With respect to illocution, rules of use can involve a reflection on what counts as good use. (As we will see with perlocution, application of use is creative in ways that the original idea of a work object or tool did not anticipate.) In other words, they are practices, whose chief feature necessary for our reflection on them is their repeatability of achieving ends. Unique to the illocution of work is not only that it performs according to convention; it also constitutes the world concretely through creating and using objects. Repeatability is therefore linked to what Arendt's notion of durability, or the capacity of work to allow for the recurrence of a similar kind of action or set of actions constituting a human world of norms and values-relaxing, building a fire, reading a book, etc. And so, in contrast to locution's instrumental use, illocutionary force entails the performance of practices according to which we can repeat those actions we find conducive to the ends of living well. Furthermore, key to the repeatability of practices is that it allows us to consider our actions as constituting a whole if for the only reason we can ask "Why do we commit to repeating these actions?" The dimension of illocution, to put it another way, is not without resource for critical reflection on its conventions. Alasdair Maclntyre's notion of practice (Sinnicks 2014: 230-31) therefore includes a capacity to rule follow as well as to question what counts as good for the worker and the organization of work. ${ }^{16}$ As Maclntyre (2016: 130-31; 170-71) points out with respect to the Japanese automobile industry after 
1951, internal reflection on the goods of work can lead to new conventions that benefit both worker and organisation. ${ }^{17}$

b) perlocution

Perlocution refers to that which is done by doing, where 'by doing' involves effects beyond the immediate content of the action and expectation of any norms governing what it means to perform an action. It concerns what Austin refers to as 'sequel' effects which 'are not conventional.' In terms of my opening remarks, we can say that perlocution refers to the efficaciousness of an action having to do with extra-constitutive effects. Searle (2005: 118) describes these in terms of effects on the listener: 'utterances normally produce, and are often intended to produce, further effects on the feelings, attitudes, and subsequent behavior of the hearers.' However, not all speech acts have perlocutionary effects (Searle 1969: 46). This is because not all speech acts are intended to produce non-conventional effects. I will return to the issue of intentionality in the next section as this feature of Searle's, and to a large extent Austin's, thesis is one from which I will depart given my analysis relies heavily on the application of the object of work. (I take application in a broad sense to include application of a tool in a given activity of work and/or application of an object produced by work and for the use of anyone who chooses to do so.)

At the moment, let us focus on the manner in which action is perlocutionary. If the analogy between discourse and action is convincing, then there is much more that needs to be explained with respect to the perlocutionary effects of action, something which Austin (1975: 107) notices but does not develop when observing there is 'an arbitrarily long stretch ... of consequences' fundamental to a conception of action. I take Ricoeur's discussion of three importance traits of action to meet the burden of trying to explain how action is open to a broad range of perlocutionary consequences. These traits are the autonomy, relevance, and openness of action (Ricoeur 1973b: 100-103).

The traits are mutually inclusive. The autonomy of action involves the manner in which any action can be freed from its original historical context and applied in other situations. This application 
is not a neutral one but has a specific aim or intention. Application is thus the application of action within a context of relevance other than the specifically historically original one. 'An important action,' writes Ricoeur (1973b: 102), 'develops meanings which can be actualized or fulfilled in situations other than the one in which this action occurred.' The openness of action is simply an extension of the role of relevance. If an action can be applied to generate a novel effect or meaning, then this implies that action is like an open work. Performed at one time, it can be taken and applied to illuminate new meanings.

So for Ricoeur action may occur as a specific event, but the event itself has a range of potential meanings. Analogous to fixed discourse, action is thus open to interpretation to 'anybody who can read' (Ricoeur 1973b: 103; italics omitted). For example, if we consider the attempt of Guy Fawkes to bomb English Parliament in 1605 as an action, Ricoeur is arguing that its meaning is not confined to its immediate historical significance, where we might connect the action to religious and political division and plans to replace King James I with a Catholic monarch. Meaning is not even confined to potential competing arguments about what may have really happened. Indeed, we find its most recent, creative application in the Anonymous protest movement, which draws on the visage of Fawkes as represented by the comic book and film V for Vendetta (Ough 2015) and which is itself an interpretation of the original action we identify with Fawkes. Action is construed in a strong sense of requiring interpretation because the range of potential meanings related to it are not consequential or sequential effects in the classical sense of action theory (Ricoeur 1973b: 115), ${ }^{18}$ but correlative.

Let us then extend these features of action to work. We have noted the autonomy of action to some extent in terms of the conventional meanings of rules of making and using. The action of work tends to free itself from the narrowly instrumental ends while the object produced in work can be taken up by anyone who wishes to use it. In the former, mowing the lawn may become attached not just to conventional expectations of a nice-looking yard but perhaps, at the extra-constitutive level, to being a work of landscape art that helps to promote one's well-being. In the latter, utile objects can be decorative or personal and hence taken out of their context of regular, intended usage. It is 
therefore tempting to ask if there can indeed be an aberrant use of a product of work so long as the defining context of use precipitates this unusual use (cf. Searle 1969: 149-50).

We might also consider sequel effects in terms of how an activity of work shapes our perceptions and conversations. The nature of everyday conversation about mowing the lawn or making a fence might flow onto other topics by mere association. Using a hammer to make a fence might, for instance, find the conversation moving towards property lines, national boundaries, a dividing wall, the state of the U.S. presidency since 2017. The flow of conversation in an associative manner is what philology terms recoverability, or 'the extent to which an element is derivable from the previous discourse record' (Geluykens 1993: 181). While the flow of conversation might not lead directly to a new application of the product or activity of work, it certainly increases the range of its potential application. All this is to say that the way in which meaningfulness arises in the course of work is due to a broader scope in which any particular act of work leaves its mark.

Implicit in these examples is the capacity of perlocution to refigure ${ }^{19}$ the way we perceive ourselves, the world, and others. I will say more about this in the next section. At this point, let me encapsulate what I have attempted to do in this section by way of the following table:

\begin{tabular}{c|c|c}
\multicolumn{2}{c|}{ Constitutive } & Extra-Constitutive \\
Locution & Illocution & Perlocution \\
\hline $\begin{array}{c}\text { use } \\
\text { task } \\
\text { instrumental }\end{array}$ & $\begin{array}{c}\text { performance } \\
\text { practice } \\
\text { conventional }\end{array}$ & $\begin{array}{c}\text { open application } \\
\text { refiguration }\end{array}$ \\
& potentially perception-changing
\end{tabular}

Simply put, meaning is predicated in three ways: 1 ) instrumental meaning, or locution; 2) conventional meaning, or illocution; and 3) extra-constitutional meaning, or perlocution. We can understand these three meanings alternatively as the meaning of fulfilling instrumental ends, the meaning of performing a task to a certain standard or expectation, and the meaning of an effect that changes how we perceive 
ourselves, the world, and others. Meaningfulness is therefore not confined to operations internal to or specific to a kind of work, as it is often assumed, but is instead a dynamic interplay between these three dimensions. As an interplay, meaningfulness is not like an end state but more a process in which one hopes to achieve some kind of equilibrium. In the final section on capabilities, we will see how this interplay can help one to evaluate one's work and sense of well-being. Finally, it is also worth recalling the theses on necessity in the conceptual and historical assumptions. The former conceives meaningfulness arising from the unavoidable nature of work, while the latter from its indispensable nature. Given the threefold distinction of meaning I have put forth, we can see some significant differences. Necessity, according to the analogy to speech acts, refers to the locutionary and illocutionary dimensions of work that meet instrumental and social (conventional) needs. The conceptual assumption could not provide an account of how non-necessary perceptions of well-being were tied to work, except as a relation of expression (of concepts we attribute to work). The analogy to speech acts has located this phenomenon in terms of work's perlocutionary effects. The historical assumption either discounts the perlocutionary as trivial because it is ideological and non-essential to our relation to material necessity, or it attempts to see locution and illocution as the 'be all' of meaningful work.

\section{Refiguration and the Extra-Constitutive Effects of Work}

I want to say a bit more about the perlocutionary dimension of work in order to emphasize its importance with regard to our capacity for innovation and creativity. Take the act of building a public road, for example. This act can be read not just at the locutionary level of essential road construction but at the illocutionary level of meeting the expectations of public works, which in this case might be allowing citizens to carry on with their commerce and commuting. Or, it might provide a network to access friends and family and thus count as a good road for social interconnectivity. We therefore find that an act of work has a plurivocity of meanings that are open to interpretation and argumentation. But what happens when we turn to an analysis of perlocution? Might road use conjure a sense of 
adventure, as when Jack Kerouac (2000: 25) writes, 'There was nowhere to go but everywhere, so just keep on rolling under the stars.' Or, contrarily, perhaps it might instil a sense of homelessness because it refigures the landscape so that it is without a real center (Augé 1995: 67). We see that perlocution neatly captures work as an activity that allows us to see and make the world in novel ways, or what I want to call its ability to refigure our perception. In fact, refiguration opens the world to us in ways that extend beyond instrumental and conventional expectations, and it would appear that because of this, perlocution matters most about work. Or at the very least, we now have a counter-balance to the view that the matter of work is about its necessity. So in what follows, I want to make the case for changing our perception about the way work is not just necessary but significantly creative.

I think we can begin to see this distinction with respect to a small point of contrast between Austin/Searle and Ricoeur. In the former, perlocution is not given much discussion in comparison to illocution. Arguably, this is because Austin (1975: 107) and Searle (1969: 46) develop their respective speech act theories according to speaker intentionality and any sequel effects are thereby limited as opposed to open, as Ricoeur would have it. ${ }^{20}$ But there is also something much more substantial at play. Considering Searle and Ricoeur on metaphorical speech acts helps to illustrate this point since both take metaphor to be meaning-creating yet by explaining the creative function in conflicting ways. Searle (1979: 85) finds fault with what he calls 'semantic interaction theories' that Ricoeur argues to be on the right track since they locate how metaphorical predication occurs in a sentence by virtue of tensions and clashes of meaning (Ricoeur 1973a; 1977: Study 3). For Searle, predication results not internal to the sentence but because the metaphorical meaning is not determined by the truth conditions of the sentence. For Searle, the hearer 'requires something more than his knowledge of the language', etc. in order to understand when a speaker intentionally makes a metaphorical assertion-when saying 'S is $P$ ' the speaker means ' $S$ is $R$ ' (1979: 84-85).

The upshot of this difference is that Ricoeur's account allows for the emergence of meaning in metaphorical utterances despite speaker intention. This is not to say speaker intention does not matter. Ricoeur's concern is rather that the hard cases for a philosophy of language and action involve 
not having access to speaker/actor intention, though we may speak or act under the pretense of doing so, as in talking about what Shakespeare meant when writing Hamlet. Ricoeur's point, and in a similar spirit Derrida's, is that we should refrain from thinking there are ideal relations of communication in which intention is transparent, obvious, or can be easily deciphered. Much of Searle's position relies on the integrity of speaker/author intention, something with which Derrida famously takes issue (cf. Moati 2014: 100; 117-18) and with which Ricoeur would agree vis-à-vis his acceptance of the autonomy of the text (Ricoeur 1991: 143, 225, 326).

So if perlocution matters most with respect to the function of work, it does so because some aspect of work allows for creative re-application regardless of an original intention of someone who makes something to be used in work. For Ricoeur, the feature of action that allows for its retrieval and re-interpretation is its inscription-like quality in which the meaning of action no longer 'coincides with logical intentions of the actors' (1973b: 102). If work is a unique species of action, then we might expect this inscription event occurring in a distinct way. In fact, we have already replied to this point in terms of the durability of work which inscribes the conventional in the world. Furthermore, this means that extra-constitutive meanings are potential and are indexed to the application of a tool or work object (as in rules of use at the instrumental and conventional levels). Or, we can say rather clumsily that they reside in potential and are activated when someone uses equipment or work objects in a novel way. Conceiving work along these lines has a distinct advantage over Searle's theory of perlocution since it can track the often spontaneous and unpredictable ways in which things are used.

Let us take another example of extra-constitutive effects in work. If we consider a shovel used in building a level foundation for the construction of a home, then the locutionary dimension would involve creation of a foundation per rules of doing so. The illocutionary dimension would call upon standards of craft and building in assessing what has been laid. The perlocutionary dimension might be something like a revelation about a sense of history when discovering the stratification of the soil when digging, perhaps prompted by finding an artifact. In a classic Heideggerian sense, the prominence of the use of the equipment recedes as we become more intrigued by the different layers 
of soil and their historical significance. And yet all the while, it was the shovel that enabled this reflection.

So how, then, should we say tools and objects of work are involved in extra-constitutive meaning predication? A short answer is to reply that any use of such an object that lends itself towards a kind of reflection and discovery of meanings beyond the immediate focus of the use of that object makes a good candidate for extra-constitutive meaning predication. A longer reply would involve specifying the various ways in which such use originates and then expands with regard to meanings beyond an immediate instrumental focus. We might consider, for example, the use of objects in building, production, acquisition, everyday activities, and service. ${ }^{21}$ Perlocutionary meanings would be defined relative to the work activity itself in order to get a sense of the remit in which they would be linked broadly to a refiguration of how we view ourselves, the world, and others. If perlocution is what matters most for work, it is not because it transcends locution and illocution. It is because perlocution characterizes what we think to be most important about work-namely, renewal.

\section{Capabilities, Work, and Speech Acts}

The meanings which I have termed extra-constitutive are properly poetic (creative) in the sense that they allow us to see ourselves, the world, and others anew (cf. Ricoeur 1973a). Because of this emphasis, meaningfulness can be said to lie in the realm of application-whether this application exists in terms of one's own job or outside one's job. What I have not commented on is how a worker within his or her own role can see his or her work as meaningful. In this section, I want to say more about this with respect to capabilities. Why capabilities?

The reason for this is mostly practical. It should be an expectation of a philosophy of work to have practical implications, and one way of doing this is to link an analysis of concepts and relations to a worker's capabilities to achieve those things that contribute to his or her flourishing. According to Amartya Sen (1993), the Capabilities Approach (CA hereafter) addresses this with respect to functionings, or those things that one identifies as contributing to what makes one's life go best. A 
group of functionings informs a specific capability (Sen 1993: 38). Nourishment is a basic functioning we all require, and the lack of it means one's life would be depleted of a basic standard of living. Having a good career might be another functioning, and though less basic than nourishment it should still figure into the overall picture of one's capability to live. In view of this, Sen's approach has the aim of creating an evaluative space in which a worker can gain a better sense of whether or not functionings are being achieved or are in conflict with one another given one's work. For instance, if Rachael values the functionings of a good career and the freedom of religion, there could be a situation where the two conflict if her work meant, for some reason, that she had to conceal her religious affiliation or if certain practices at work clashed with a religious precept that she held. CA would allow Rachael to recognize this conflict and to reflect on the extent to which the conflict was insuperable and problematic. ${ }^{22}$ If the ongoing achievement of functionings is seen to comprise meaningfulness, selfevaluation then becomes a matter of determining which and how many functionings are affirmed. So what does the analogy to speech acts add?

Let us hearken back to one of my central concerns about the reduction of meaningfulness to beliefs and feelings about one's work (the conceptual assumption). CA breaks this reduction by turning to valued functionings which are arguably objective in the sense that as a human being and as a member of a particular community, a certain range of functionings deemed to be essential and important will inform our understanding. ${ }^{23}$ However, where CA wavers to some extent is on the linkage between one's work and these functionings. Is it the case that some functionings are inherent to forms of work? Is it a matter of a person believing it to be the case and asserting so? Is it a mixture of both?

The analogy to speech acts allows us to see meaningfulness and functionings in terms of the three dimensions of performance: the instrumental (locutionary), conventional (illocutionary), and extra-constitutive (perlocutionary) effects. Furthermore, the specifically extra-constitutive dimension of perlocution allows one to distinguish a broader sphere in which functionings clearly extend beyond work-specific ends. With the example of Rachael, it could be argued that the functionings of a good 
career and freedom of religion should not really be bundled together as long as the latter was not substantially violated. (Let us assume for the sake of argument that the conflict involves a consulting business whose work has the potential of clashing with a religious precept against usury since a bulk of its main clients consist in mortgage lenders.) Someone might therefore argue-perhaps a Kantian who takes Kant's notions of public and private seriously - that the means and ends innate to the workplace are those which should be kept separate from other (public) ends. In one sense this is true-that is, in an instrumental (locutionary) sense of achieving work-specific targets, and in a conventional (illocutionary) sense of the quality of performing one's job. The non-conventional (perlocutionary) effects may not be directly related to the work but could in fact have higher standing in relation to non-work values, especially if their extra-constitutive nature is one that affects Rachael's perception of herself, the world, and others.

Let us say that in Rachael's case, the conflict with usury arises by a series of associations where consulting for businesses that lend money is linked by her to the housing market, which in turn is linked by her to her own community where such a market has resulted in problems involving the proliferation of second homes, on the one hand, and foreclosures, on the other hand. Her community is depleted of regular neighbors, and not only has the value of property made it difficult for her to own a home (due to increased speculation by aspiring second-home owners) but the communal ethos has been diluted. So what sense can Rachael make of this conflict? Whatever she decides, my account of the poetics of work would enable her to see and explore how work-related ends stand against other ends that are by no means less significant since such ends can be identified within a wider scope of meaningfulness. When the analogy to speech acts and CA are taken in tandem, then we not only have a method of determining whether one's work is making one's life go well, but also a way of seeing the points of contact, affirmation, and conflict that perform this.

If I have made a convincing case for the unique way in which work functions, I want to conclude with a few remarks on two limitations that would require further analysis and comment. First, how 
extensively are we to take this analogy to speech acts? Should we be content with it as a heuristic device which begs ontological and metaphysical questions about what work is really like? Does this heuristic mean we are merely relying on some kind of linguistic representation or correlation of a fundamental action and confess that we can never really know its true nature? My inclination is to say heuristics is helpful in this case because it latches on to what is true about work even though we may not have a metaphysical account that explains why work is discourse or discourse-like. The paradox is: Can we ever rely on a non-materialistic means of accurately representing the meaning of a material action? Obviously, without further argumentation, trusting in the analogy to discourse risks a kind of idealism about linguistic universality for which hermeneutics is known. Presumably further consideration would provide a compelling account of how a reflection on the fundamental nature work should not seek some origin absent of non-material relations (à la Marx) but acknowledge a version of the hermeneutical circle in which work is bound up (already) with those actions, rules, practices, modes of being, and forms of life that are non-material and symbolic. Whatever the case, the claim that this circular relation between work and discourse is virtuous must here, in this version of the poetics or work, remain its presupposition.

Second, what I have not done is provide a way of determining which kinds of work are potentially more meaningful by virtue of their locutionary, illocutionary, and perlocutionary effects. A potential criticism of what I have presented lies in the allegation that my account could be used to justify and valorize degrading forms of work as long as it can be shown there is some form of meaning predication involved. I have omitted commenting on this because such a task goes well beyond the poetics that I intended to outline and reaches towards questions of justice. Nonetheless, the view I have presented is not without resources to respond to this criticism. Linking the poetics to CA means recognizing and taking seriously the evaluative space in which one can compare and contrast functionings and how they are being affirmed or denied. A more complete role for CA would involve evaluating the range of functionings of any one person or community from the outside-are the functionings a worker takes seriously themselves problematic? But far from being unaddressed 
problems for the view I have proposed, I see the poetics of work as providing a firm ground upon which political and ethical concerns can be pursued constructively. 


\section{References}

Arendt, Hannah (1958) The Human Condition. Chicago: University of Chicago Press.

Attfield, Robin (2001) 'Meaningful Work and Full Employment', Reason in Practice 1(1): 41-48.

Augé, Marc (1995) Non-Places: Introduction to an Anthropology of Supermodernity. John Howe (trans.). London: Verso.

Austin, J. L. (1975) How to Do Things with Words, Second Edition. Oxford: Clarendon Press.

Arneson, Richard J. (1987) 'Meaningful Work and Market Socialism', Ethics 97(3): 517-545.

Bailey, Catherine and Adrian Madden (2015) 'Time reclaimed: temporality and the experience of meaningful work', Work, Employment, and Society 31(1): 3-18.

Cadman, Emily (2016) 'Services close to 80\% of UK economy' Financial Times, March 31, 2016; accessible at https://www.ft.com/content/2ce78f36-ed2e-11e5-888e$\underline{\text { 2eadd } 5 \mathrm{fbc} 4 \mathrm{a} 4 \text { ? mhq5j=e1 }}$

Cavell, Stanley (1995) 'What Did Derrida Want of Austin?', Philosophical Passages: Wittgenstein, Emerson, Austin, Derrida. Oxford: Blackwell, pp. 42-65. (1958) 'Must We Mean What We Say?', Inquiry 1(1): 172-212.

Chalofsky, Neal (2003) 'An emerging construct for meaningful work', Human Resource Development International 6(1): 69-83.

Gheaus, Anca and Lisa Herzog (2016) 'The Goods of Work (Other Than Money!)', Journal of Social Philosophy 47(1): 70-89.

Geluykens, Ronald (1993) 'Topic Introduction into English Conversation', Transactions of the Philological Society 61(2): 181-214.

Gomberg, Paul (2007). How to Make Opportunity Equal. Oxford: Blackwell.

Heidegger, Martin (1962). Being and Time. John Macquarrie and Edward Robinson (trans). Oxford: Blackwell.

Honneth, Axel (2008) Reification: A New Look at an Old Idea. Oxford: Oxford University Press. 
- (2007) 'Rejoinder' in Bert can den Brink and David Owen (eds) Recognition and Power: Axel Honneth and the Tradition of Critical Social Theory. Cambridge: Cambridge University Press, pp. $348-370$.

Hornsby, Jennifer (1998) 'Free Speech and Illocution', Legal Theory 4: 31-37.

Hursthouse, Rosalind (2001) On Virtue Ethics. Oxford: Oxford University Press.

Kenny, Anthony (1963) Action, Emotion and Will. London: Routledge \& Kegan Paul.

Kerouac, Jack (2000)[1955] On the Road. London: Penguin.

Langton, Rae (1993) 'Speech acts and unspeakable acts', Philosophy and Public Affairs 22 (4): 293330.

Lau, R. S. M. (2000) 'Quality of work life and performance - An ad hoc investigation of two key elements in the service profit chain model', International Journal of Service Industry Management 11(5): 422-437.

Maclntyre, Alasdair (2016) Ethics in the Conflicts of Modernity: An Essay on Desire, Practical Reasoning, and Narrative. Cambridge: Cambridge University Press.

Marx, Karl (1988) Economic and Philosophic Manuscripts of 1844. M. Milligan (trans). Amherst: Prometheus Books.

(1976) Capital, Volume III. B. Fowkes (trans). Harmondsworth: Penguin.

Maslow, Abraham (1994)[1971] The Farther Reaches of Human Nature. New York: Arkana.

Moati, Raoul (2014) Derrida/Searle: Deconstruction and Ordinary Language. Timothy Attanucci and Maureen Chun (trans). New York: Columbia University Press.

Muirhead, John (2004) Just Work. Cambridge, MA: Harvard University Press.

Murphy, James Bernard (1993) Moral Economy of Labor: Aristotelian Themes in Economic Theory. New Haven: Yale University Press.

Nussbaum, Martha C. (2011) Creating Capabilities: The Human Development Approach. Cambridge, MA: Belknap Press. 
Ough, Tom (2015) 'Anonymous: How the Guy Fawkes mask became an icon of the protest movement', Independent, November 4, 2015; accessible at http://www.independent.co.uk/news/uk/home-news/anonymous-how-the-guy-fawkesmask-became-an-icon-of-the-protest-movement-a6720831.html

Ricoeur, Paul (1991) A Ricoeur Reader: Reflection and Imagination, ed. Mario J. Valdés. New York: Harvester Wheatsheaf. (1986) Lectures on Ideology and Utopia, ed. George H. Taylor. New York: Columbia University Press.

(1977) The Rule of Metaphor: Multi-disciplinary Studies of the Creation of Meaning in Language. R. Czenry, K. McLaughlin, and J. Costello (trans). London: Routledge \& Kegan Paul. -------- (1973a) 'Creativity in Language', Philosophy Today 17(2): 97-111.

--------- (1973b) 'The Model of the Text: Meaningful Action Considered as a Text', New Literary History 5(1): 91-117.

Roessler, Beate (2012) 'Meaningful Work: Arguments from Autonomy,' The Journal of Political Philosophy 20(1): 71-93.

Sayer, Andrew (2011) 'Habitus, Work and Contributive Justice', Sociology 45(1): 7-21.

(2009) 'Contributive Justice and Meaningful Work', Res Publica 15(1): 1-16.

Sayers, Sean (2007) 'The Concept of Labor: Marx and His Critics', Science and Society 71(4): 431-454. Schwartz, Adina (1982) 'Meaningful Work', Ethics 92: 634-46.

Searle, John (1979) Expression and Meaning: Studies in the Theory of Speech Acts. Cambridge: Cambridge University Press.

--------- (1969) Speech Acts: An Essay in the Philosophy of Language. Cambridge: Cambridge University Press.

(1968) 'Austin on Locutionary and Illocutionary Acts', The Philosophical Review 77(4): 405424. 
Searle, John and Daniel Vanderveken (2005) 'Speech Acts and Illocutionary Logic' in Daniel Vanderveken (ed) Logic, Thought and Action. Dordrecht: Springer, pp. 110-132.

Sen, Amartya (1993) 'Capability and Well-Being' in Martha C. Nussbaum and Amartya Sen (eds) The Quality of Life. Oxford: Clarendon Press, pp. 30-53.

Sinnicks, Matthew (2014) 'Practices, Governance, and Politics: Applying Maclntyre's Ethics to Business', Business Ethics Quarterly 24(2): 229-249.

Smith, Nicholas H. (2009) 'Work and the Struggle for Recognition', European Journal of Political Theory $8(1): 46-60$.

(2007) 'The Hermeneutics of Work: On Richard Sennett', Critical Horizons 8(2): 186-204.

Steger, Michael, Bryan Dik, and Ryan Duffy (2012) 'Measuring Meaningful Work: The Work and Meaning Inventory' Journal of Career Assessment 20(3): 322-337.

Veltman, Andrea (2016) Meaningful Work. Oxford: Oxford University Press, 2016.

--------- (2015) 'Is meaningful work available to all people?', Philosophy and Social Criticism 41(7): 725747.

------- (2010), 'Simone de Beauvoir and Hannah Arendt on Labor', Hypatia 25(1): 55-78.

Walsh, Adrian (1994) 'Meaningful Work as a Distributive Good', The Southern Journal of Philosophy 32: $233-250$.

Yeoman, Ruth (2014) 'Conceptualising Meaningful Work as a Fundamental Human Need', Journal of Business Ethics 125: 235-51.

\footnotetext{
${ }^{1}$ Acknowledgements.

${ }^{2}$ On 'normative', see Cavell (1958: 189-196).

${ }^{3}$ In Great Britain, for example, it is estimated that the service industry is $80 \%$ of the nation's economy; Cadman (2016).

${ }^{4}$ Andrea Veltman (2010: 65) notes that the term productionist refers to a classical economic distinction between productive and unproductive labor. While service industries inevitably use objects in their respective tasks, the classical notion of production avers that service does not produce wealth. Today, we have broader notions of
} 
what counts as value-creation. For more on the classical bias and its philosophical underpinnings, see (reference omitted for blind review).

${ }^{5}$ For a detailed account of this, see (reference omitted for blind review).

${ }^{6}$ Veltman (2010: 71) notes Arendt's criticism of Marx that his elevation of labor as the highest activity tends to increase consumptive behaviour as opposed to actions characteristic of self-actualization or eudaimonia.

${ }^{7}$ Steger et al's (2012: 323-325) claim about work involving eudaimonic growth is no exception since they do not give a justification of how eudaimonia is objective or universal-i.e., not just a matter of personal growth. On eudaimonia and relativism, see Hursthouse (2001). Testimony about meaningful work has been referred to as the worker's perception of 'an authentic connection between their work and a broader transcendent life purpose beyond the self' (Bailey and Madden, 2015: 4). The focus in such sociological studies is not so much that there is, objectively speaking, a meaningful essence or nature to work, but more an integral link between an attitude or perception of well-being and one's work (Chalofsky 2003: 73; cf. Muirhead 2004: 8).

${ }^{8}$ Examples of conceptual association vary. One commonality is the idea that reference to certain attributes or effects is an exemplification of work's capacity to instantiate meaningfulness. Beate Roessler (2012: 74) notices a similar problem and opts instead to define work according to a broad spectrum of values, which includes autonomy, non-alienation, and social recognition (cf. Schwartz 1982). Yet Roessler only associates work with existential and political concepts. James Murphy (1993) and Adrian Walsh (1994) define work in terms of theoretical (conception) and practical (execution) dimensions-i.e. how the two interrelate in any activity of work. But note that the association can be deemed accidental, or as Hume might say imagined, since the relation can be coincidental or correlative but not integral. For example, Walsh (1994: 245-46) sees meaningfulness arising via a self-reflective process in which the theory one holds and uses in relation to an activity, such as painting, is open to revision by means of reflecting on the obstacles and problems one encounters. The worry here is that the interplay between theory and practice seems too general and does not appear to distinguish anything unique about the way in which work produces meaning. An activity like playing snooker might achieve the same ends, and we might question on most occasions whether this was work. Veltman (2016) dedicates a chapter to discussing what makes work meaningful, offering a detailed analysis of how meaning is multidimensional and becomes involved in ways that can be missed if we are interested in a singular definition of meaningfulness. But again, the links are associative, where what makes work meaningful is the fact that we observe such things as self-respect, a sense of purpose, or the exercise of skill as arising from work. 
${ }^{9}$ I omit discussion of Searle's (1968; 1969: 29-30) criticism of Austin's distinction between locutionary and illocutionary utterances since Ricoeur follows Austin. At some level, the distinction between locution and illocution is problematic with respect to what Searle (1968) notes in terms of some sayings (constatives) relying on illocutionary content to determine the sense-reference relation and indeed that locution and illocution are often bound up with one another.

${ }^{10}$ There is an interesting point of comparison in how Ricoeur and Austin regard action. Austin (1975: 112) refers to 'minimum physical' acts as those acts which seem to lack a vocabulary for naming them since nomenclature with action tends to be tied to its consequences. Action, properly speaking, already figures into the realm of communication, convention, and effect. So non-minimal actions are already imbued with a sense and reference (locution) as well as some conventional significance (illocution). Ricoeur (1986: 255-56) would say, following Clifford Geertz's The Interpretation of Cultures (1973), that non-minimal action is already symbolic.

${ }^{11}$ Following Heidegger (1962: 97/68), I will designate this use of objects as equipment [das Zeug].

12 I leave aside economic constraints, such as how mass production or control of the means of production by a few influences the quality of work. These are important matters but outside the remit of this essay.

${ }^{13}$ My thanks to XXX for noting this connection.

${ }^{14}$ I make a liberal use of Arendt since although I rely on her analysis of work, my assumption that work is an action can be construed as incompatible with her distinctions between labor, work, and action. I press this point further in section three when equating work with renewal, or as Arendt might say, natality. There is perhaps room to argue that some form of work might, on Arendt's view, reach the status of action. Art does only because it is non-utilitarian. My claim that work is creative and extra-constitutive may be compatible with this view in some respect.

15 This relation may be a bit cumbersome given that Searle (1969: 154-55) refers to a distinction between meaning and use, or truth conditions and function, respectively. The term 'meaning' relates to the analysis of description and not meaning in the sense I intend it with regard to work and its world-constituting function. This difference merely anticipates a disagreement about what the creative function of discourse is. I discuss this briefly with respect to metaphor in the third section.

${ }^{16}$ Linking illocution to practice would require addressing important issues raised by Rae Langton (1993) and Jennifer Hornsby (1998) about illocution, authority, and freedom that I leave here untreated.

${ }^{17}$ My thanks to XXX for referring me to Maclntyre (2016). 
${ }^{18}$ Ricoeur's reference to these terms means that in applying the analogy, one would have to revise Austin's understanding of sequel effects as being directly intended or related. Indeed, I attempt to do so in the next section. Also to note: there is a parallel here between Ricoeur's notion of autonomy of action and Derrida's understanding of intentionality (or lack thereof) in speech acts. What Ricoeur describes under the banner of interpretation, Derrida describes under iteration. See Raoul Moati (2014: 38-40).

${ }^{19}$ Comment and reference omitted for blind review.

${ }^{20}$ Austin (1975: 107) does recognize unintentional effects to some extent yet not significantly.

${ }^{21}$ I have discussed an example of building with respect to the shovel. Let me briefly note details about the other categories. Production includes the use of capital goods in the classical economic sense of things used to produce things of value. Acquisition involves the use of things to acquire natural resources. What I am calling everyday activities, for lack of a better term, encompasses the use of those objects we rely upon to perform our daily tasks that are not directly related to the kind of work we associate with a paid career or job. It can also include the non-use of objects as when they are on display or stored for future use or simply for appreciation (aesthetic, sentimental, or otherwise). Finally, service is an umbrella term for those activities that may not result in the production of an object but nonetheless use such objects in carrying out a conventionally recognized task of value.

${ }^{22}$ Sen's account is, of course, more complex. For one, he sees different bundles of functionings arising in different situations. See Sen (1993: 38-50).

${ }^{23}$ Sen (1993: 48-49) wishes to keep the range of functionings incomplete while Nussbaum (2011) argues for a more prescriptive list of capabilities that can form rights to capabilities. 